\title{
Thermal Stability of Inorganic Pigments Synthesized from Galvanic Sludge
}

\author{
MARIA-IULIANA MARCUS ${ }^{1}$, MARIA VLAD ${ }^{2}$, GYÖRGY DEÁK ${ }^{1 *}$, ANDREEA MONCEA ${ }^{1}$, \\ ANA-MARIA PANAIT ${ }^{1}$, GELU MOVILEANU ${ }^{3}$ \\ ${ }^{1}$ National Institute for Research and Development in Environmental Protection - INCDPM, 294 Splaiul Independentei, \\ 060031, Bucharest, Romania \\ 2"Dunărea de Jos" University of Galati, Faculty of Engineering, 47 Domnească Str., 800008, Galati, Romania \\ ${ }^{3}$ Valahia, University of Targoviste, Romania, 2 Carol I Blvd, 130024, Targoviste, Romania
}

\begin{abstract}
Pigments used in ceramic glazes have been obtained by chromium ions extraction from galvanic sludge and their precipitation as barium chromate and lead chromate from technological solutions. The chemical composition was determined by XRF method. Complex thermal analysis TGDSC, XRD and SEM methods have been used for microstructural characterization and thermal treatment behaviour evaluation, in order to establish the compatibility with the ceramic matrix. XRD spectra have highlighted only lead chromate specific interferences in the monoclinic phase and barium chromate in the orthorhombic phase, suggesting an advanced degree of purity. Weight losses of 2.2\% for barium chromate and $3.1 \%$ for lead chromate have been recorded on the TG curve at $800^{\circ} \mathrm{C}$. As a result of thermal treatment, barium chromate has changed its colour from yellow to green.
\end{abstract}

Keywords: galvanic sludge, inorganic pigments, thermal stability

\section{Introduction}

The industrial developments cause an increasing in the concentrations of heavy metal ions from industrial effluent, such as electroplating sludge [1]. The pollution with heavy metals represents an important global issue because of their extremely toxic effect even at low concentrations and one of the highest environmental risk is the omnipresence of heavy metals due to their toxicity, persistence and lack of biodegradation [2-4]. There are various methods for neutralization and recovery of electroplating sludge, namely: methods of incorporation/inertisation of the sludge (also heavy metals) in stable matrices and methods for the extraction of valuable components (metal ions) and their exploitation such as inorganic pigments or raw materials in various industries [5].

Inorganic pigments are used in many industries. Pigments used in the ceramic industry are inorganic compounds such as metal oxides, mixture of metal oxides or metal salts [6]. Generally, the quality of ceramic pigments depends on their crystalline structure, chemical composition, purity and physical characteristics [7]. Ceramic industry is on the rise and constant competitiveness in this sector and is leading manufacturers and researchers to find solutions in order to reduce raw materials costs and, at the same time, to develop new products. In recent years, a particular attention was given to the recycling of industrial waste, which are a source of alternative and less expensive raw materials $[8,9]$. Various methods were developed in order to synthesize pigments from high metal ion containing sludge such as: green and pink pigments synthesized from high-chromium galvanic sludge [10]; red, green, pink ceramic pigments synthesized from sludge from various metal coating processes and having high aluminum and chromium content [8]; red-brown and black pigments obtained from high chromium and iron sludge resulting from the treatment by electrocoagulation of wastewater from metallic coatings and tested in transparent ceramics [11]; yellow and brown pigments obtained from metallurgical dust and tested in glazes and angobes [12] or gray-black ceramic pigments synthesized from sludge resulted from chromium/nickel/cooper metal coating activities [13]. The latest research in the field has focused on the synthesis of ceramic pigments from tannery wastewater treatment sludge [14-16].

\footnotetext{
*email: dkrcontrol@yahoo.com
} 
In this work, we focus on the characterization of yellow and orange chromium based pigments such as barium chromate and lead chromate, synthesized from galvanic sludge. The main purpose of the research was to study the microstructural characterization and thermal treatment behavior of pigments, in order to establish the compatibility with the ceramic matrix. Generally, these pigments have a good thermal stability and coloring strength [17]. Their use is limited by the Restriction of Hazardous Substances (RoHS) Directive, therefore researches on their valorization has focused on obtaining ceramic materials for decorative use that do not come into contact with food.

\section{Materials and methods}

\subsection{Pigments synthesis}

Chromium based pigments were extracted from a sludge which is the result of the treatment of mixed wastewaters derived from various metal finishing processes (copper plating, cadmium plating, zinc plating, etc.). The sludge presented a complex chemical composition, the content in metals being the following: $8.00 \%$ chromium; $21.3 \%$ iron; $2.44 \%$ zinc; the content of $\mathrm{Ni}, \mathrm{Cu}, \mathrm{Cd}, \mathrm{Pb}, \mathrm{Mn}, \mathrm{Ca}, \mathrm{Mg}$, $\mathrm{Na}$ being below $1 \%$ for each element [18]. Sludge samples were dried at 1050C in Binder oven to constant weight, about $6 \mathrm{~h}$ and milled in ball grinding mill in order to obtain particles with average diameters of about $20 \mu \mathrm{m}$.

The chromium recovery process was based on the solubilisation of trivalent chromium by alkaline oxidation with $12 \%$ sodium hypochlorite and $20 \%$ sodium hydroxide added to provide a strong alkaline medium $(p \mathrm{H}=12.0-12.5)$; reaction temperature was $80^{\circ} \mathrm{C}$, reaction time $30 \mathrm{~min}$, with stirring throughout the reaction. Reagents consumption was calculated from chemical reactions, the amount of sludge processed and its chromium content. The samples were filtered with a vacuum pump resulting a sodium chromate solution from which the chromium-based pigments were extracted. The extraction efficiency of chromium ions was $84.20 \%$ in one stage [19]. Lead chromate was obtained by precipitation process with lead acetate $\left[\mathrm{Pb}\left(\mathrm{CH}_{3} \mathrm{COO}\right)_{2} 3 \mathrm{H}_{2} \mathrm{O}\right]$ and barium chromate was obtained by precipitation with barium chloride $\left[\mathrm{BaCl}_{2} 2 \mathrm{H}_{2} \mathrm{O}\right]$. The precipitates were vacuum-filtered, the cakes were washed stepwise in order to remove the soluble salts adsorbed on the cake, dried and prepared by grinding [20].

\subsection{Methods of investigation}

The chemical composition of both pigments was determined by XRF spectrometry using an X-Ray Fluorescence Supermini instrument. The purity of synthesized pigments from sludge was also determined by X-ray diffraction analyzes using a D8 Advance Diffractometer in the $\theta-2 \theta$ configuration with $\mathrm{Cu} \mathrm{K \alpha l}$ radiation $(\lambda=0.154060 \AA)$. The data were obtained by scanning in the range of $2 \theta=10$ $70^{\circ}$ with a step of $0.02^{\circ}$. The morphology of both lead chromate and barium chromate raw and thermal treated at $700^{\circ} \mathrm{C}$ respectively $800^{\circ} \mathrm{C}$ was investigated by scanning electron microscopy (SEM) using a Hitachi SU-70 FE-SEM model. DSC (Differential Scanning Calorimetry) and TG (Thermo Gravimetry) analyzes at different temperatures according to the particularities of the materials and their chemical composition was performed in order to investigate the behavior of the pigments at heating (phase transformations and mass losses). Heating behavior of pigments was studied using a Netzsch STA 449 F5A. The TG and DSC curves were recorded in nitrogen atmosphere using alumina crucibles. The investigated temperature range was $25-800^{\circ} \mathrm{C}\left(\right.$ or $850^{\circ} \mathrm{C}$ ) at a heating rate of $10^{\circ} \mathrm{C} / \mathrm{min}$.

\section{Results and discussions}

The chemical composition of both barium chromate and lead chromate pigments determined by $\mathrm{XRF}$ analyses is presented in Table 1 . 
Table 1. Elemental composition of barium chromate and lead chromate

\begin{tabular}{cccccc}
\hline Pigment & \multicolumn{5}{c}{ Elemental composition (mass \%) } \\
\cline { 2 - 6 } & $\mathbf{C r}$ & $\mathbf{B a}$ & $\mathbf{P b}$ & $\mathbf{S}$ & Minor components \\
\hline Barium chromate & 25.1 & 72.8 & - & 1.3 & 0.8 \\
\hline Lead chromate & 23.6 & - & 75.2 & - & 1.2 \\
\hline
\end{tabular}

The XRF results highlight the purity of the synthesized inorganic pigments. Thus, the barium chromate pigment contains mainly barium (72.8\%) and chromium (25.1\%). The $1.3 \%$ of sulfur derived from synthesis process and the rest of the components does not exceed $1 \%$. The lead chromate pigment contains lead as major component $(75.2 \%)$ and chromium in proportion of $23.6 \%$, the minor components does not exceed $1.2 \%$. The XRD patterns of synthesized barium chromate particles are presented in Figure 1. The sharp diffraction peaks indicate that the product is well crystallized. Accordingly, to ICDD (International Centre for Diffraction Data) database all the interferences were perfectly indexed as orthorhombic phase of barium chromate with lattice parameters of $a=9.103 \AA, b=5.526 \AA$ and $c=7.337 \AA$. On the $x$-ray pattern the interferences belonging to other phases are not recorded indicating that the minor components appeared during the synthesis reaction are poorly crystallized. For the lead chromate patterns presented in Figure 2, all the interferences were indexed as a single phase of monoclinic lead chromate [space group P21/n (14)] with lattice parameters $\mathrm{a}=7,12 \AA, \mathrm{b}=7,43 \AA, \mathrm{c}=6,79 \AA$ and $\beta=102,420^{\circ}$ consistent with the reported data (JCPDS 73-2059).

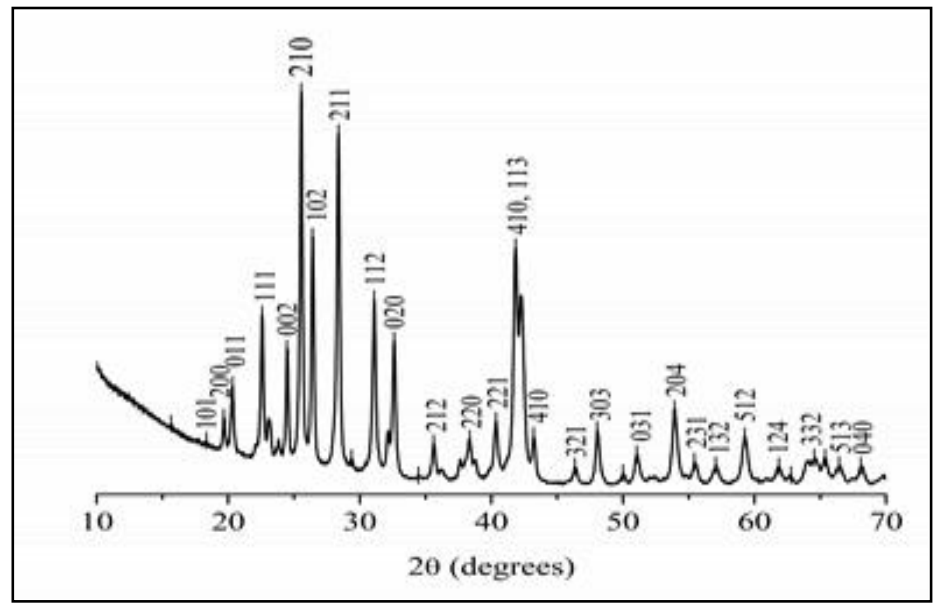

Figure 1. XRD spectra of barium chromate pigment

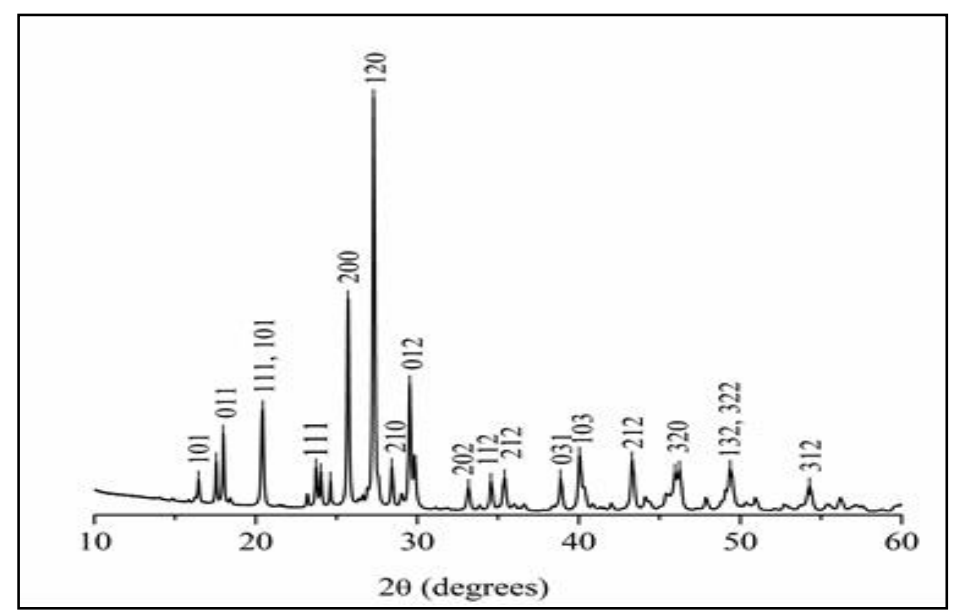

Figure 2. XRD spectra of lead chromate pigment 
The morphology of both barium chromate and lead chromate raw and thermal treated at $800^{\circ} \mathrm{C}$ respectively $700^{\circ} \mathrm{C}$ was investigated by scanning electron microscopy (SEM). In Figure 3 are presented the SEM images of raw and thermal treated barium chromate at $800^{\circ} \mathrm{C}$, The raw barium chromate powder has a fine texture and a unimodal distribution of the grains, with agglomeration tendency of the very small size particles. After sintering at $800^{\circ} \mathrm{C}$ (Figure 3b), results a pore-free structure, in which the polyhedral granule (with well-defined sides and edges) are about $5 \mu \mathrm{m}$ in size.

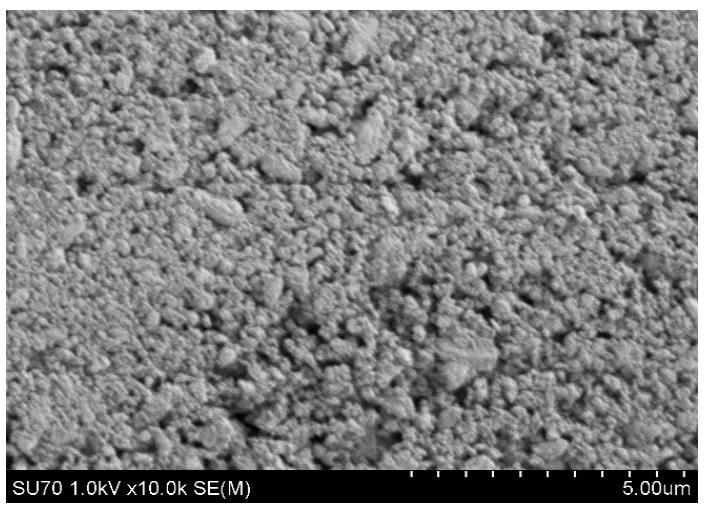

$a$

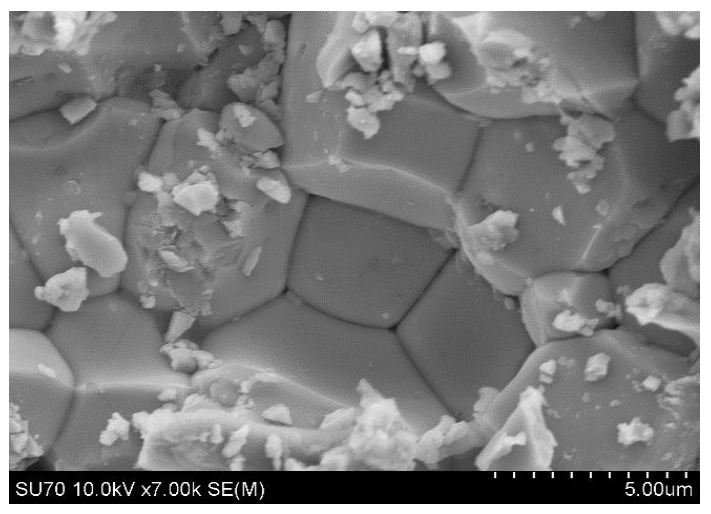

$b$

Figure 3. SEM images of barium chromate, raw (a) and thermal treated at $800^{\circ} \mathrm{C}$ (b)

The micrographs of raw lead chromate, presented in the Figure 4, evidence polyhedral granules which exhibit a bimodal distribution, without agglomerations; the size of the large particle varies between $1 \mu \mathrm{m}$ to $2 \mu \mathrm{m}$ and the small particles do not exceed $0.4 \mu \mathrm{m}$. The sintering at $700^{\circ} \mathrm{C}$ ensure the formation of a compact structure, through an intimate grains linkage, with visible intergranular boundaries and triple junctions (Figure $4 \mathrm{~b}$ ). The particle sizes may reach up to $8 \mu \mathrm{m}$, highlighting the positive temperature effect on the grain growth rate. Araújo et al. has evidence a high rate of the granule growth, hence a good reactivity of lead chromate, by thermal treatment up to $700^{\circ} \mathrm{C}$ [21].

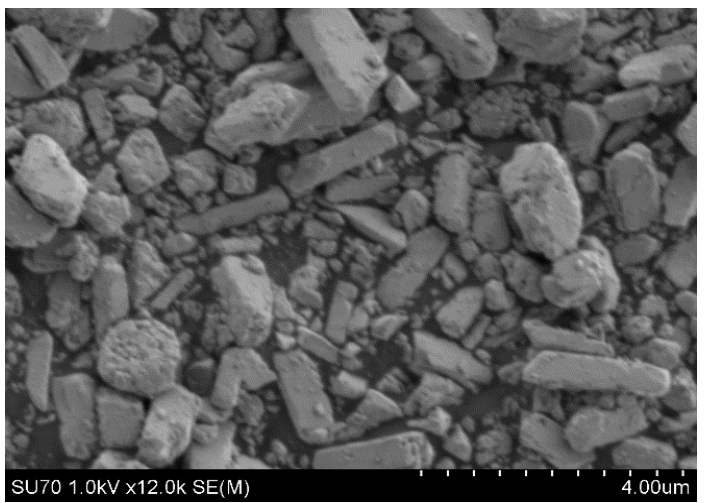

$a$

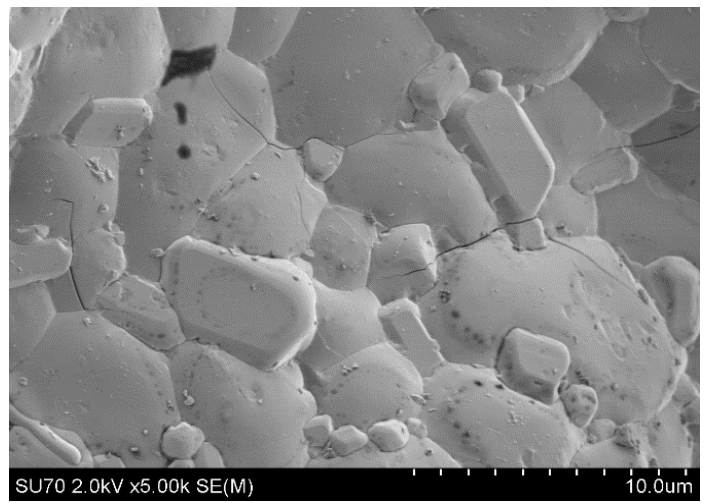

$b$

Figure 4. SEM images of lead chromate, raw (a) and thermal treated at $700^{\circ} \mathrm{C}$ (b)

SEM images of the ceramic body interface with the transparent glaze, containing $5 \%$ barium chromate are presented in Figure 5. The fixing of the glaze on the ceramic body surface was accomplish by heating at $1100^{\circ} \mathrm{C}$. At the interface area the glaze diffuses into the surface layer of the crystalline and porous ceramic body (Figure $5 b$ ). 


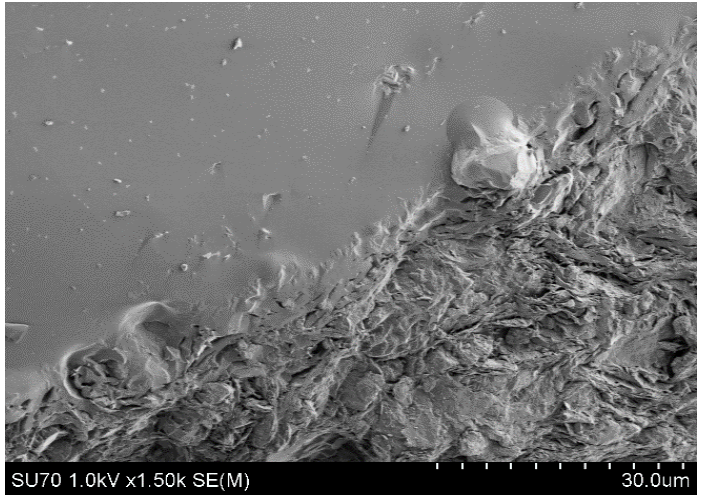

$a$

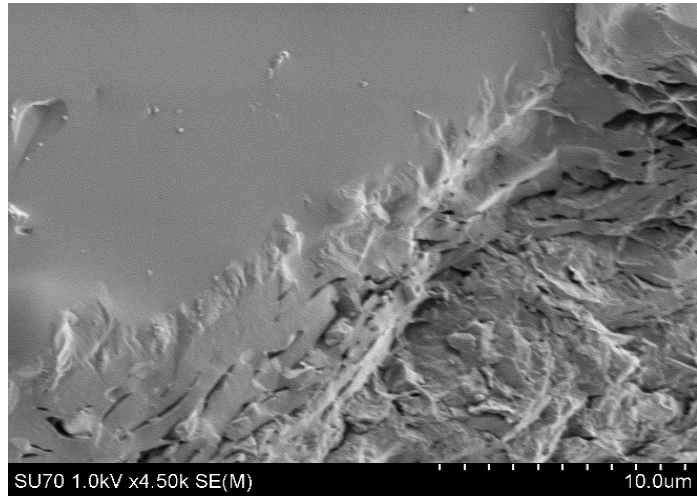

$b$

Figure 5. SEM image of the ceramic body interface with glaze containing $5 \%$ barium chromate, at different magnifications.

The thermal stability of the pigments was studied in nitrogen medium by complex thermal analisis. In Figure 6, TG-DSC curves coresponding to lead chromate are presented.

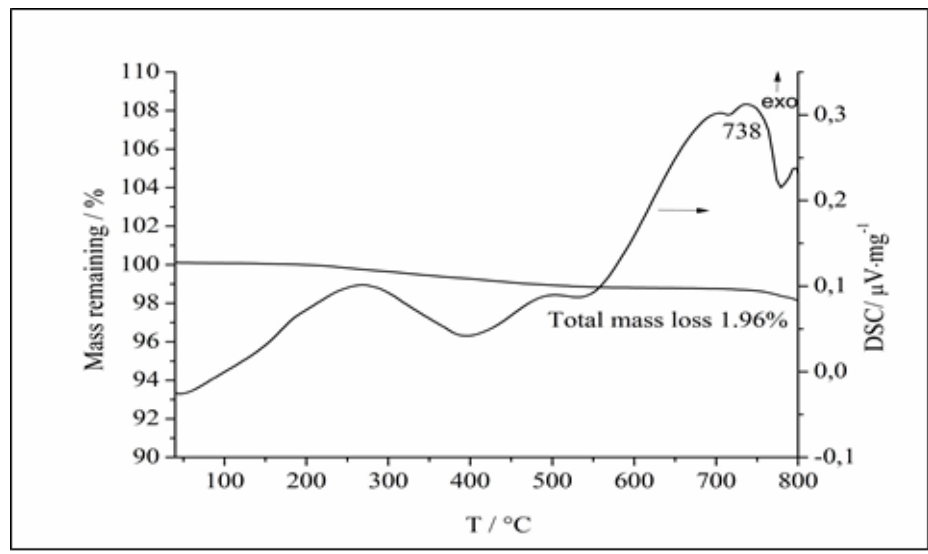

Figure 6. DSC-TG curves of the lead chromate, synthetized from galvanic sludge

There is an exothermic effect indexed on DSC curve, with a maximum to $738^{\circ} \mathrm{C}$, accompanied by a mass loss of $0.72 \%$. The thermal effect corresponds to the phase transformation of the monazitestructure in the high temperature baryte form. The total mass loss registrerd on TG curve of the lead chromate was $1.96 \%$. From scientific data, pure lead chromate, obtained by synthesis, presents at high temperature two phase tranzitions: from the low temperature monazite structure passes at $706^{\circ} \mathrm{C}$ into the $\beta$ - barite form and at $782^{\circ} \mathrm{C}$ into the $\gamma$ - barite [22]. In this case lead chromate, obtained by synthesis from galvanic sludges, contains $1.2 \%$ minor components, which could be the reason of why the temperature at which it undergoes phase transformations may be different. Knight reported that the phase transition from the monazite structure of synthetic lead chromate in the barite structure was achieved at $795^{\circ} \mathrm{C}$, and the process was accompanied by a mass decrease of $1.6 \%$ [23].

DSC curve of the barium chromate recorded a thermal effect between $570^{\circ} \mathrm{C}$ and $770^{\circ} \mathrm{C}$ (with a maximum at $650^{\circ} \mathrm{C}$ ), to which it corresponds a mass loss of $0.25 \%$ (Figure 7). 


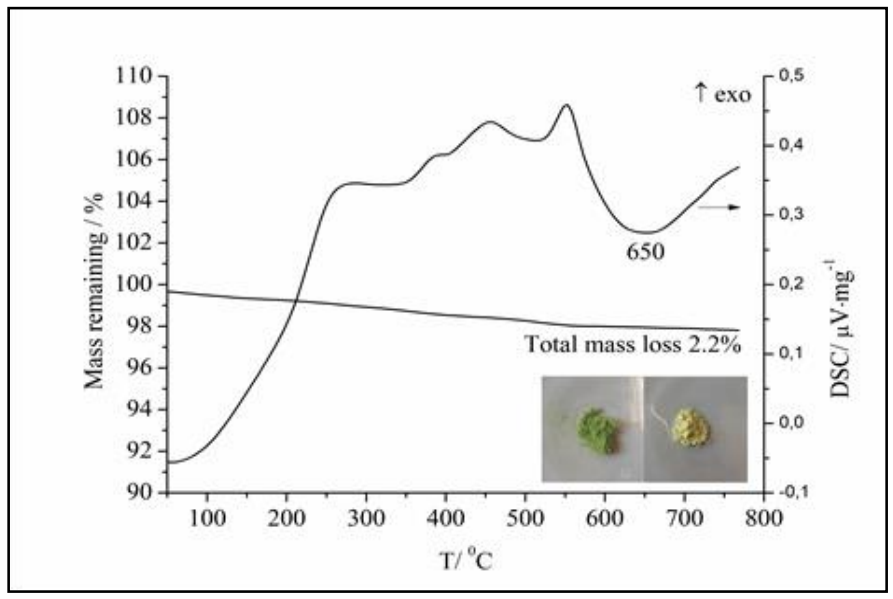

Figure 7. DSC-TG curves of the barium chromate, synthesized from galvanic sludge

Unlike lead chromate, the color of barium chromate, at the end of the analysis, changed from yellow to green, suggesting its decomposition into the nitrogen atmosphere. There are various data regarding the thermal stability of barium chromate in different gaseous environments. Decomposition of barium chromate is accompanied by oxygen release and reduction of chromium [24]. In some papers research it is mentioned that barium chromate is thermally stable up to $850^{\circ} \mathrm{C}$ [25]. In other sources it states that between 800 and $900^{\circ} \mathrm{C}$, it decomposes into a mixture of $\mathrm{BaCr}_{2} \mathrm{O}_{4} /$ $9 \mathrm{BaO} \cdot 4 \mathrm{Cr}_{2} \mathrm{O}_{3} \cdot \mathrm{CrO}_{3}$, according to the $\mathrm{BaO}-\mathrm{Cr}_{2} \mathrm{O}_{3}$ phase diagram [26]. In air, barium chromate has thermal stability up to $1400^{\circ} \mathrm{C}$; partial oxygen pressure could inhibit the decomposition mechanism of barium chromate [10]. By vacuum sintering at $1050^{\circ} \mathrm{C}$, barium chromate changes its color from yellow to green, suggesting its decomposition and formation of $\mathrm{BaCr}_{2} \mathrm{O}_{4}$ [11]. In this case, the decomposition of barium chromate is accelerated by the reducing charachter of the nitrogen atmosphere. The total weight loss recorded at the end of the determination was $2.2 \%$.

\section{Conclusions}

The XRF analyses highlighted the purity of the synthesized pigments: the major component of lead chromate pigment is lead (75.2\%), followed by chromium (23.6\%); Barium chromate pigment contains mainly barium (72.8\%) and chromium (25.1\%). In both cases the amount of impurities is very low (less than 1.2\%). The XRD analyses highlighted single phases of monoclinic lead chromate and orthorhombic barium chromate. For lead chromate the DSC/TG analyses highlighted an exothermic effect with a maximum at $738^{\circ} \mathrm{C}$, accompanied by a mass loss of $0.72 \%$ corresponding to the phase transformation of monazite-structure into barite form. For barium chromate, the DSC curve recorded a thermal effect between 570 and $770^{\circ} \mathrm{C}$ with a mass loss of $0.25 \%$. At the end of the thermal treatment the color of barium chromate, changed from yellow to green, suggesting its decomposition. The total weight loss recorded at the end of the determination was 2.2\%. The SEM images of raw lead chromate highlights dispersed polyhedral grains, bimodal distributed while the sintered pigment exhibits a compact structure, through an intimate grains linkage, with visible intergranular boundaries and triple junctions. The SEM images of raw barium chromate highlights a powder with fine texture and a unimodal distribution of grains, with agglomeration tendency of the very small size particles. The sintered sample at $800^{\circ} \mathrm{C}$ presented a pore-free structure, in which the polyhedral granule (with welldefined sides and edges) are about $5 \mu \mathrm{m}$ in size.

From microstructural point of view, at the ceramic/glaze matrix interface, a transition area can be delimited where the glaze, by diffusion mechanisms, has been fixed to the ceramic body surface. 
Acknowledgments: Research activities that underline the work have been performed in the laboratories of National Institute for Research and Development in Environmental Protection Bucharest. The authors would like to thank the INCDPM management for its support.

\section{References}

1. KAMAR, F.H., NECHIFOR A.C., MOHAMMED A.A, ALBU P.C., CRACIUN M.E., Removal of Lead and Cadmium Ions from Aqueous Solution using Walnut Shells as Low-Cost Adsorbent Materials, Rev. Chim., 66(5), 2015, 615-620

2. IONESCU, P., RADU, V.M., DEAK, GY., DIACU, E., Distribution, Partition and Fluxes of Trace Heavy Metals in the Lower Danube River, Rev. Chim., 65(9), 2014, 1092-1095

3. IONESCU, P., DEAK, GY., DIACU, E., RADU, V.M., Assessment of Heavy Metals Levels in Water, Sediments and Fish from Plumbuita Lake, Romania, Rev. Chim., 67(11), 2016, 2148-2150

4. ANGHEL, A.M., DEAK, G., IONESCU, P. et all, Danube River Basin Waters on Romanian Territory: Chemical Status Assessment Based on Priority Substances Data Analysis, Rev.Chim., 70(9), 2019, 3292-3298

5. MITIU, M.A., MARCUS, M.I., VLAD, M., BALACEANU, C.M., Stability of Ceramic Glazes Obtained by Valorification of Anorganic Pigments Extracted from Electroplating Sludge, Rev. Chim., 69(3), 2018, 571-574

6. BARBA, A., GAZULlA, M. F., GOMEZ, M. P., ORDUNA, M., Characterisation of cobaltcontaining ceramic pigments by WD-XRF and XRD, X-RAY SPECTROMETRY, X-Ray Spectrom., 35(6), 2006, 383-389

7. COSTA, C. E. F., CRISPIM, S. C. L., LIMA, S. J. G., PASKOCIMAS, C. A., LONGO, E., FERNANDES, Jr. V. J., ARAÚJO, A. S., SANTOS, I. M. G., SOUZA, A. G., Synthesis and thermal characterization of zirconium titanate pigments, J. Therm. Anal. Calorim., 75, 2004, 467-473

8. COSTA, G., RIBEIRO, M. J., TRINDADE, T., LABRINCHA, J. A., Development of waste-based ceramic pigments, Bol. Soc. Esp. Ceram. V., 46(1), 2007, 7-13

9. HAJJAJI, W., COSTA, G., ZANELli, C., RIBEIRO, M.J., SEABRA, M.P., DONDI, M., LABRINCHA, J.A., An overview of using solid wastes for pigment industry, J. Eur. Ceram. Soc, 32(4), 2012, 753-764

10. ANDREOLA, F., BARBIERI, L., BONDIOLI, F., CANNIO, M., FERRARI, A.M., LANCELLOTTI, I., Synthesis of chromium containing pigments from chromium galvanic sludges, $J$. Hazard. Mater., 156, 2008, 466-471

11. TEZCAN UN, U., ONPEKER, S.E., OZEL, E., The treatment of chromium containing wastewater using electrocoagulation and the production of ceramic pigments from the resulting sludge, J Environ Manage, 200, 2017, 196-203

12. OVČAČÍKOVÁ, H., VLČEK, J., KLÁROVÁ, M., TOPINKOVÁ, M., Metallurgy dusts as a pigment for glazes and engobes, Ceram. Int., 43(10), 2017, 7789-7796

13. GARGORI, C., PRIM, S.R., LUSAR, M.L, FOLGUERAS, M.V., MONRÓS, G., Recycling of $\mathrm{Cr} / \mathrm{Ni} / \mathrm{Cu}$ plating wastes as black ceramic pigments, Mater. Lett., 218, 2018, 341-345

14. DU, M., DU, Y., CHEN, Z., LI, Z., YANG, K., LV, X., FENG, Y, Synthesis and characterization of black ceramic pigments by recycling of two hazardous wastes, Appl. Phys. A, 123, 2017, 575

15. LI, Z., DU, Y., CHEN, Z., SUN, D., ZHU, C., Synthesis and characterization of cobalt doped green ceramic pigment from tannery sludge, Ceram. Int., 41(10), part A, 2015, 12693-12699

16. HARTANTI, L.P.S., Potential use of chrome-tanned leather waste as ceramic pigment, International Journal of Management and Applied Science (IJMAS), 3(9), 54-57

17. BAE, B., WENDESU, TAMURA, S., IMANAKA, N., Novel environmentally friendly inorganic yellow pigments based on gehlenite-type structure, Ceram. Int., 42, 2016, 15104-15106 
18. MARCUS, M.I., VLAD, M., MITIU, M.A., ANGHEL, A.M., MARINESCU, F., LASLO, L., ILIE, M., SZEP, R., GHITA, G., MATEI, M., HOLBAN, E., DUMITRU, F. D., Recovery of galvanic sludge by physicochemical mechanisms, Journal of Environmental Protection and Ecology JEPE, 18(3), 2017, 1117-1126

19. MARCUS, M.I., VLAD, M., MITIU, M.A., Influence of different galvanic sludge types on the extraction efficiency of chromium ions, Adv Mat Res, 1143, 2017, 108-113

20. MARCUS, M.A., MITIU, M.A., VLAD, M., MINCU, M., GHITA, G., ANGHEL, A.M, Influence of Different Electroplating Sludge Types on the Iron Ions Recovery Yield, Rev. Chim., 69(3), 2018, 618-620

21. ARAÚJO, V. D., ANDREETA, M. R. B., MAIA, L. J. Q., NASCIMENTO, R. M., MOTTA, F. V., BOMIO, M. R. D., PASKOCIMAS, C. A., BERNARDI, M. I. B., Microstructural, structural and optical properties of nanoparticles of $\mathrm{PbO}-\mathrm{CrO}_{3}$ pigment synthesized by a soft route, Ceramica, $\mathbf{6 1}$, 2015, 118-125

22. JAEGER, F. M., GERMS, H. C., Über die binären Systeme der Sulfate, Chromate, Molybdate und Wolframate des Bleies, Journal of Inorganic and General Chemistry, 119(1), 1921

23. KNIGHT, K. S., A high temperature structural phase transition in crocoite $\left(\mathrm{PbCrO}_{4}\right)$ at $1068 \mathrm{~K}$ : crystal structure refinement at $1073 \mathrm{~K}$ and thermal expansion tensor determination at $1000 \mathrm{~K}$, Mineral. Mag., 64(2), 2000, 291-300

24. GONTARZ, Z., Analysis of the steps of thermal decomposition of oxo-compounds of the dsp block elements, J. Therm. Anal. Calorim., 43(1), 1995, 57-68

25. LIANG, X. S., OUYANG, J. H., LIU, Z. G., Influences of temperature and atmosphere on thermal stability of $\mathrm{BaCrO}_{4}$, J. Therm. Anal. Calorim., 111(1), 2013, 371-375

26. OUYANG, J. H., SASAKI, S., MURAKAMI, T., UMEDA K., Spark plasma-sintered $\mathrm{ZrO} 2(\mathrm{Y} 2 \mathrm{O} 3)-\mathrm{BaCrO}_{4}$ self-lubricating composites for high temperature tribological applications, Ceram. Int., 31, 2005, 543-553

$\overline{\text { Manuscript received: } 23.01 .2020}$ 